\title{
INTEGRATED PLATFORM FOR REAL-TIME CONTROL AND PRODUCTION AND PRODUCTIVITY MONITORING AND ANALYSIS
}

\author{
${ }^{I}$ G. G. Vieira, ${ }^{2}$ M. L. R. Varela, ${ }^{3}$ G. D. Putnik, ${ }^{4}$ J. M. Machado, ${ }^{5} J$. Trojanowska \\ 1,2,3 Department of Production and Systems, ${ }^{4}$ Department of Mechanical Engineering, \\ School of Engineering, University of Minho, Guimarães, Portugal \\ ${ }^{5}$ Poznan University of Technology, Management and Production Engineering, Poznan, Poland \\ Igaspar_vieira@hotmail.com,${ }^{2}$ leonilde@dps.uminho.pt,${ }^{3}$ putnikgd@dps.uminho.pt, ${ }^{3}$ jmachado@dem.uminho.pt , \\ ${ }^{4}$ justyna.trojanowska@put.poznan.pl
}

\begin{abstract}
In this paper is proposed the IndustSystems, which is an integrated platform that aims at controlling and monitoring of production and evaluation of productivity in real time, via web access, using hybrid and scheduling algorithms that allow management and optimized use of production resources and perfect synchronization of production flows.
\end{abstract}

Keywords: real time control of production, integrated platform.

\section{Introduction}

This paper aims at putting forward the implementation of a platform for industry, the IndustSystems for controlling and monitoring, in realtime, production and productivity levels through web access. This supervision and management will allow for a rationalization and optimization of resources in order to obtain a perfect synchronization of production flows.

The work carried out aims to support industry in general, but was already implemented on a textile factory, for promoting competitiveness and significantly increasing production capacity, using the integration of a set of logically settled activities, involving equipment, users, procedures and information.

The knowledge about industrial activity is essential for an accurate construction of tools to promote appropriate design and implementation of production and marketing strategies.

In this study were conducted market studies for collecting data, from several distinct sources, to obtain a broad set of information that could clarify about the likelihood of success of an implementation of a new entrepreneurial project.

An exploratory study was conducted in order to gather preliminary information that could help in the analysis of the potential of this project.

This study was based on several visits performed to companies linked to the textile confection industry where this study took primary place, in order to realize the activity in general and their specific kind of operation, along with collected opinion of those who had for long time been dedicated to textiles, to realize how we could collaborate in the preparation and implementation of algorithms for supporting management and control tasks of existing technical resources and simultaneously for being able to stimulate their competitiveness by streamlining and integrating various technologies.

Therefore, through our proposed platform our main aim consists on contributing to added value for companies, through the achievement of encouraging results for all stakeholders. For managers, to increase the productivity substantially, since it will enhance a more uniform performance, thus being able to reward those who achieve the company's goals. Regarding employees, they may be able to better realize about their work performed and to improving their work, thus promoting a level of both constant and effective performance.

There was carried out research on existing technology, in particular the equipment used in this type of industry, as well as contacts with some businesses and suppliers of equipment to ascertain the existing solutions on the market and better understand what are their expectations, and what kind of cooperation could be feasible for implementation of our proposed platform.

Our main aim is to develop and deliver innovative solutions that can help companies improve processes that can enable companies to reach a state of excellence. Therefore it is considered a project with high competitive advantage, not just regarding what it represents for the industry in general, but also for providing industry with tools, for improving its economy.

The IndustSystems provides technology and software engineering solutions for production optimization and rationalization of industrial resources and processes.

This platform is being developed from scratch in order to fill a gap in this market, through the creation of 
a more effective production control and monitoring platform. The main project idea is to explore and leverage a new project channel based on a centralized platform for the provision of real-time information inherent in the control and management of productivity.

This project aims to meet a gap in the textile industry on the production control in real time, to manage production processes and report them in an automated way. The project enables automatic monitoring of the entire production process in the textile factory studied.

The company will provide solutions and services for the industry in general (besides the textile industry), for automating processes and routines, analysis and development of algorithms able to control, manage and optimize real-time production.

In order to better present the work carried out in this project, this paper will start with a brief literature review about real time manufacturing support systems and tools. After, the proposed platform is presented and some main functionalities described and illustrated. Finally, some conclusions and future work intentions are referred.

\section{Literature review}

The concept of real time management is not new, and we can place the first real experience when, in the late 50's, was developed in the United States a real time information management system in order to strengthen the air defence country (Everett, Zraket \& Benington, 1957). In the 90s, Wu \& Kaiser (1993) designed the architecture of a monitoring system to support real-time management, whose main function was to correct exceptional conditions within specific time constraints. Later, Haynes, McGregor \& Stewart (1997) defined "real-time management" as the current processing information at any time and the feedback concerning their performance should reflect the actuality of events. Otherwise, the company will "pro-duce a product for which the market no longer required it" or "solve a problem but disappeared in the same period."

In real-time control, the critical factors are the collection of data, fast processing, short answer and instant feedback (Monostori et al., 2010). The automatic identification methods and capture information (Automatic Identification and Data Capture, AIDC) is responsible for the data collection, automatically and in real time then present themselves two of these methods: Collection through radiofrequency and sensors.

The Radio Frequency Identification (RFID) is not a new technology and was initially used for military purposes during World War II (Zhang et al., 2012).

RFID has several benefits when implemented in a production system, from identification to distance, continuous screening products, real-time control and their operability in severe conditions (Brewer, Sloan \& Landers, 1999).

Technology has also been widely used in information capture in real time (Gunasekaran, Ngai \& McGaughey, 2006). Companies such as BMW and
Vauxhall use RFID tags to ensure complete accuracy in customizing each order. These tags are programmed with customer requirements to subsequently monitor the car during its production process. Thus, employees have no doubts about the specifics of the operations to be undertaken (Zhekun, Gadh \& Prabhu, 2004).

The sensors are transducers that make measurements on the conditions of the "real world," transforming phenomena from physical into electrical signals (López, Ranasinghe, Patkai \& McFarlane, 2011) (Voicu \& Gheorghe G., 2014). There are several types of methods and devices for measuring a certain phenomenon, varying according to the price, size, accuracy and range desired (Alexandru, C. \& Gheorghe, G., 2014).

Sensory devices are the most common elements in management systems in real time as they collect information on a multitude of parameters. According Soloman (2009), their inte-gration, when synchronized with the strategic plan of the company, allowing achieving the fol-lowing results:

- Increased productivity - lower cost per unit;

- Increased quality - more uniform and consistent products;

- Increased reliability - fault mitigation and errors do to a better control;

- Lead time reduction - shorter delivery times;

- Improved machines occupation - higher occupancy rate of the machines.

Currently, sensors already play an important role in the production. However, Soloman provides a significant increase in the influence exerted as sensors become more technologically advanced.

According to $\mathrm{Wu}$ (1998), a distributed system is apparently equal, to its users, regarding all other systems, but different than those others by running from a set of autonomous processing elements (Processing Elements, PEs).

In other words, when the system is distributed it has the following attributes:

1. Arbitrary number of processes (logical resources);

2. Arbitrary number of PEs (physical resources);

3. The notification shall be made through an exchange of messages;

4. Cooperation between processes;

5. The delay in communication between two PEs, which should not be neglected;

6. The failure of a process or PEs not prevent the system continues to function;

7. The system will provide ways to reconfigure the system topology or the allocation of re-sources in the presence of resources failed.

In turn, Tanenbaum \& Van Steen (2007) pointed out the major goals of a distributed sys-tem: resource sharing, openness, concurrency, scalability, fault tolerance and transparency.

The sharing of resources refers to the ability to use any hardware, software or information anywhere in the system. The resources manager controls access to resources and sets the rules of interaction between user and resources. 
In its origin, a distributed system was thought for future extensions and improvements, where new features needed to be integrated with existing resources.

An important property of distributed systems is "concurrence", which manifests when there are two processes running simultaneously. System integrity can be violated if there is lack of coordination between two competing processes.

Scalability refers to the adaptability of systems to increase their speed of response and support new users. It should not be required to replace components when the scalability of a system increases.

Other two important features of distributed systems are its availability, though limited, when there is a failure of a resource, and its transparency for the user, who sees the system as a whole and not as a set of multiple components that cooperate.

Moreover, performance indicators are very important too, representing a set of measures defined by an organization, being critical for the current and future success of a distributed system. In other words, "a performance indicator is a quantified data that measures the effectiveness of all or part of a process or system in relation to a norm, a plan or a goal that should be provided and accepted in the framework of an overall strategy "(Courtois et al., 2007; Parmenter, 2010).

The recent advances in microelectronics, ubiquitous computing and wireless communication technologies are enabling to develop technologically advanced products, known as smart objects (Zhang et al., 2011). These smart devices have the capability to collect and store data in real time, to identify them and to make decisions, in an automatic and autonomous way. Thus, it is expected they will play an increasing key role in real-time management for manufacturing support. Based on these assumptions, the present work defines functions performed by smart objects, to allow a decision making based on data updated to the second, instead of the traditional reports last for days, weeks or even months.

\section{Proposed platform}

The innovative nature of this project idea is based on the use of a platform, which pro-vides the end customer, through an interface "user friendly", real-time supervision of the productivity of each operator/ operation, allowing a rationalization of existing resources more efficiently. This control is the development and integration of modules able to communicate with each other and report the information to a server so they can be reachable locally or re-motely via web.

Next are summarized the main functionalities included in the proposed platform, about production management, including several planning and control functions, along with quality management and control and automation ones.

\section{Production Management: Planning and Control}

The IndustSystems management functions for supporting production planning and control, uses a diversified ser of parameters, which are set according to the each specific area of implementation in an organization, through a prior analysis of its main processes and functional requirements and needs:

- Transforms data without value-added into valuable information, turning it available to those who need it;

- Promotes a paper-free solution (paperless) in an organization;

- Is easy to use and implement, providing the means and tools to a enable an increase in productivity in an organization.

- Order Management;

- Budgeting;

- Production Planning;

- Needs Calculation;

- Manufacturing orders and materials planning;

- Record production (materials and/ or time);

- Production monitoring;

- Identification by barcode;

- Production costs;

- Inventory Control;

- Inventories for portable terminals;

- Planning of Shipping and Registration;

- Project Expedition.

\section{Quality Management and Control}

The IndustSystems is also a quality management software:

- A Document management software that integrates all main document types (Word, Excel, PDF, Sig, Photos, etc.) with the e-mail software and backend systems and tools.

- Information system;

- Processes optimizes, transforming data without value into valuable information, making it available to those who need it;

- It consists of several modules that can be added and configured according to customer needs.

- It was developed as an evolutionary platform, subject to periodic updates according to customer suggestions, and needs. Moreover, if necessary, it can be supplemented with customized organization's measures.

\section{Other Management Functions}

1) Document Management

- Internal Documents Control (Distribution Control versions and obsolete control, approval cycles of control with automatic notification to entities involved, etc.);

- Documents on outside Control;

- Control of Records;

- Records Management;

- Document Management Associated and integrated with the records: In all modules IndustSystems Management / Quality control from production to quality, there is the possibility of associating documents and templates to all records so that information is 
always where it should be, without the need to create additional document structures;

- Quality Documents in Digital Format (Quality Manual, Quality Policy, Procedures, Work Instructions, etc.);

- Registration of Correspondence Sent and Received;

- Internal mail (mail between users, automatic warnings messages, reminders, etc.);

- Operation with any type of documents (Word, Excel, PowerPoint, Acrobat (PDF), Image, Sound and Video, etc).

2) Strategic Management

- Objectives Planning;

- Planning and Improvement Actions Monitoring;

- Monitoring Indicators;

- Meeting Minutes Control;

- Improvement Suggestions Control;

- Members of Document Management.

3) Planning

- Quality Calendar;

- Automatic dialing of regular activities;

- Automatic notifications related parties.

4) Audits

- Plans Audit; Checklists for audits (Check Lists);

- Control and Tracking Findings;

- Associate of Document Management (Report audits, objective evidence, etc.).

5) Customers

- Customers file; Customer Complaints Management;

- Complaints Statistics (by type of complaint, by article, by client, etc.);

- Cost of Claims;

- Document Management functions (evaluation of satisfaction surveys, correspondence with customers, quality reports, etc.).

6) Suppliers

- Suppliers files;

- Supplier qualification control / material control plans and receiving control records;

- Event Log (Fault) Suppliers;

- Occurrence Statistics (by type of occurrence, by article, by supplier, etc.);

- Suppliers Occurrences; Suppliers Automatic evaluation;

- Auto Emission Assessment Letter for each Supplier;

- Associated Document Management (correspondence with suppliers, quality reports, etc.).

7) Human Resources

- Employees File;

- Function Definition Framework;

- Training Plans Management;

- Curriculum Management;

- Cost Control with training plans;

- Statistics about several Training Plans (number of shares, assessment results, etc.);
- Management of documents about associated employees and training plans (Resumes, Summary and Evaluation of Training Actions, Attendance lists, Diplomas, etc.).

8) Projects

- Project management (research and development projects or other proposals);

- Predictability and control of all activities related to a project (review, verification, validation, change control);

- Management text (industrial or laboratory) associated with the project;

- Budgeting and project planning and control;

- Document management associated with projects (in any format).

\section{Control and Automation}

Development of a box which already has a prototype called IndustBox to replace the PLC (Omron, Siemens etc.) On the market at a much lower cost:

- This is a module that allows an organization to supervise and monitor the entire factory or company. From a shopfloor plant of a factory (layout) this function enables to define variables to control at each point and equipment in a factory;

- Communicating with IndustBox, allowing to visualize, in real time, the variation in variables such as: temperature, pressure, number of produced pieces, etc., on each machine and each operator;

- Defining alerts through the emission of warnings on the screen;

- Warnings on Beeps or mobile phones (with pre message - recorded) and voltage of shares;

- Automatic sending by e-mail.

- Infrastructure management and Dynamic Multicriteria Control (DMC)

- Inventory and Monitoring of Equipment and Measuring Devices;

- Maintenance Plans and Interventions Registration on equipment subject to maintenance and respective components, keeping the history of used parts.

- Plans and calibrations registration;

- Maintenance and Calibration Cost Control;

- Statistics about various Maintenance and Calibration actions (maintenance time, costs, number of interventions by equipment, etc.).

\section{Video and Chat}

- Video calls and voice calls;

- Instant messages;

- Conference calls;

- Group video calling;

- Group Screen Sharing;

- File transfers via FTP;

- Monitoring video/ audio;

- Partners advertising;

- No need for internet connection. 


\section{Platform Architecture and Illustration}

Several architectures can be proposed for the control of distributed systems (Alexandru, C. \& Gheorghe, G., 2015).

In our proposed platform a manufacturing resources (MR) can be any provider of any service, machine tool type, human agents as service providers (designers, managers, machine operators, planners, schedulers, drivers, vendors, and others), computing resources, software, among others. A MR receives the orders from internal or external 'clients' and then negotiations are triggered (for example via chat, video conferencing, or email). After the approval of an order, the resource establishes direct relationship with the client and executes the production order. The resource may give permission for the client to see the production order to be executed and may allow the client to control its use on distance (when the resource is a machine, a computer or software), either from the control room, the PC, or from a mobile device, and can even be remotely operated (Vieira et al, 2016). Figure 1 illustrated the platform architecture implemented in the textile factory studied and Figure 2 some of the main forms of implementation according possible interactions that can be established with different kind of machines, tools or other peripherals.

\section{Indust Systems}

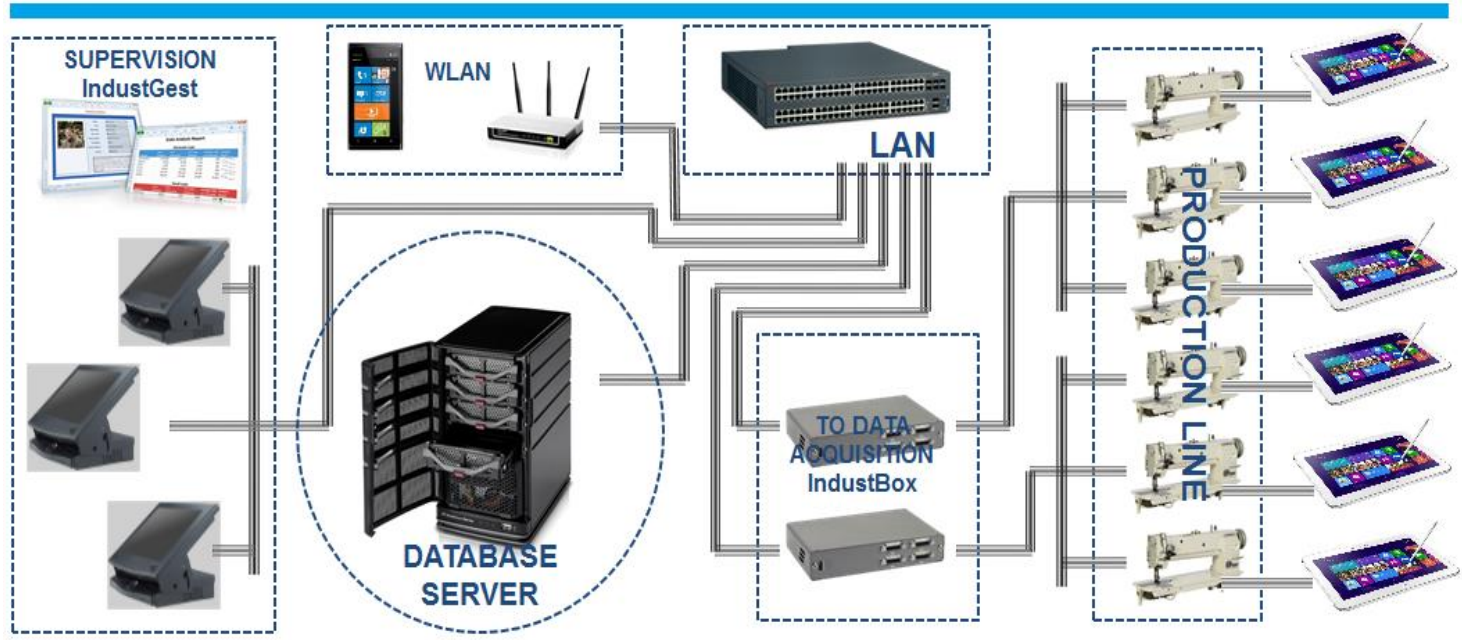

Figure 1: Platform architecture (adapted from Vieira et al., 2016)
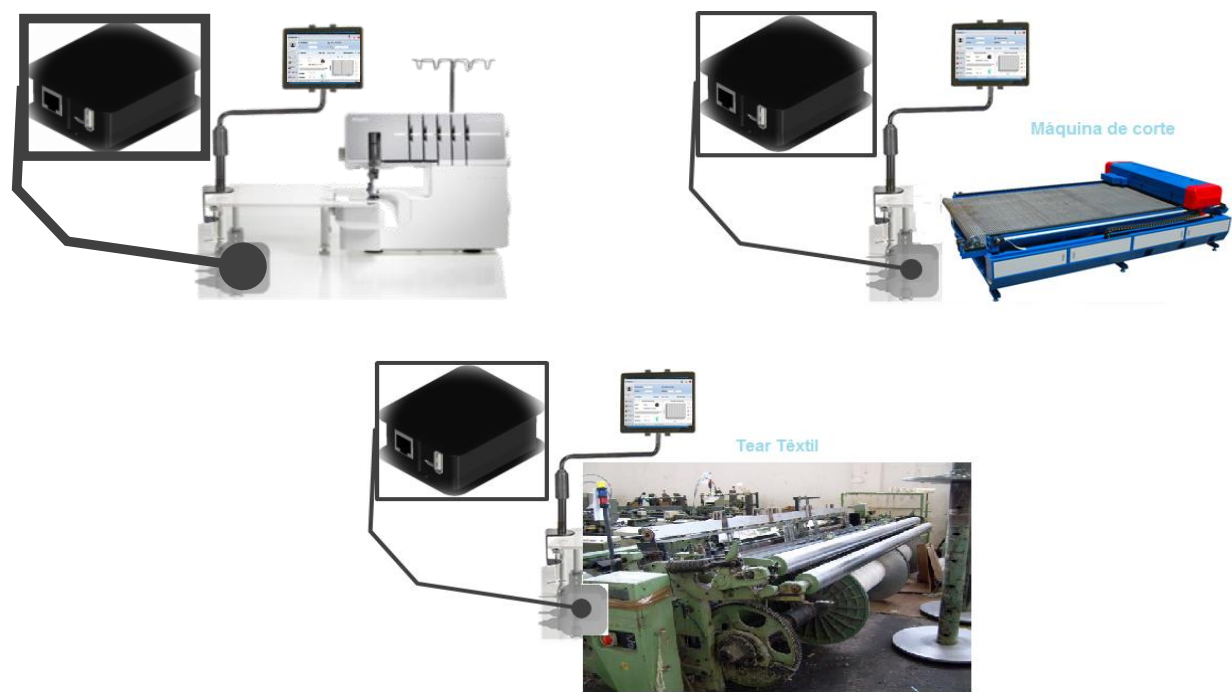

Figure 2: Main forms of hardware and software implementation.

In this context, it is essential to specify what type of information is required to be collected by these technologically advanced devices, in other words, what are the functions to be performed, to enable increased productivity and efficiency of all manufacturing resources, along with the employees involved in production.

In this context, smart objects are used, which are advanced instruments that enable to support decision making and production management, including production planning and control, for instance, regarding: 
1. Real time management functions;

2. Production management decision support;

3. Production system's performance measurement and visualization;

Important functions of the proposed platform include the production system monitoring and performance calculation, based on smart objects technology, along with the control of machines and products. Dashboards and performance indicators have an important role in this direction, as it is through these devices that it is possible, to visualize and evaluate the data captured and processed by smart objects.

In the proposed platform has been implemented a knowledge base system (KBS) in Visual Basic (VB) language as a prototype applied in the studied textile company. The VB language enables easy prototyping, as well as user friendly interfaces for data visualization and processing. Data and corresponding processing approaches and applications are managed in different ways, which is of particularly importance in the context of decentralized manufacturing scenarios. For instance, in the context of globally distributed manufacturing environments, where different and distributed schedulers are developed by different IT stakeholders, as their schedules cannot be visualized by a common viewer without particular adapted programs.
This actually causes a huge effort on a system's implementation, and both the cost and the risk of the system, which will be increased. Using interfaces developed through $\mathrm{VB}$ enables end users to have a personalized scheduling viewer, among other interfaces for supporting decision making, within a whole networked environment. Figures 4 to 7 illustrate some system's interface for the textile industrial application, which aims at enabling integrated and automatic processes and routines, along with corresponding data acquisition and processing, in a real-time basis, for production records by order, product and operator. An underlying proposed IndustBox hardware prototype developed is shown in Figure 3 and the corresponding software tool interface is illustrated in Figure 7.
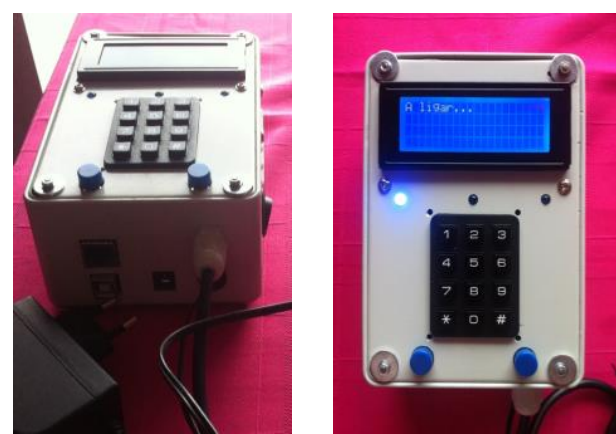

Figure 3: IndustBox hardware prototype.

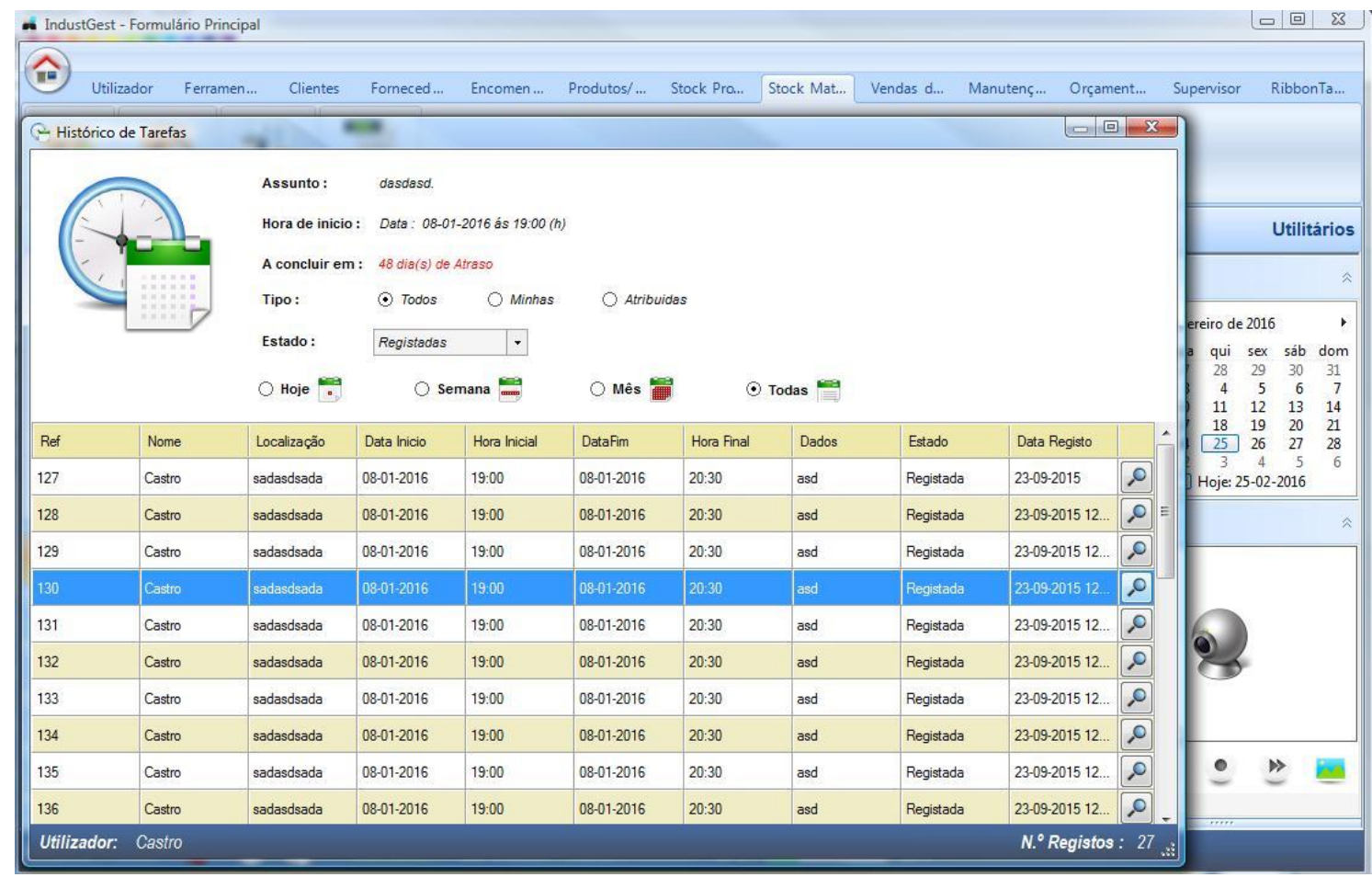

Figure 4: Orders scheduling tool. 


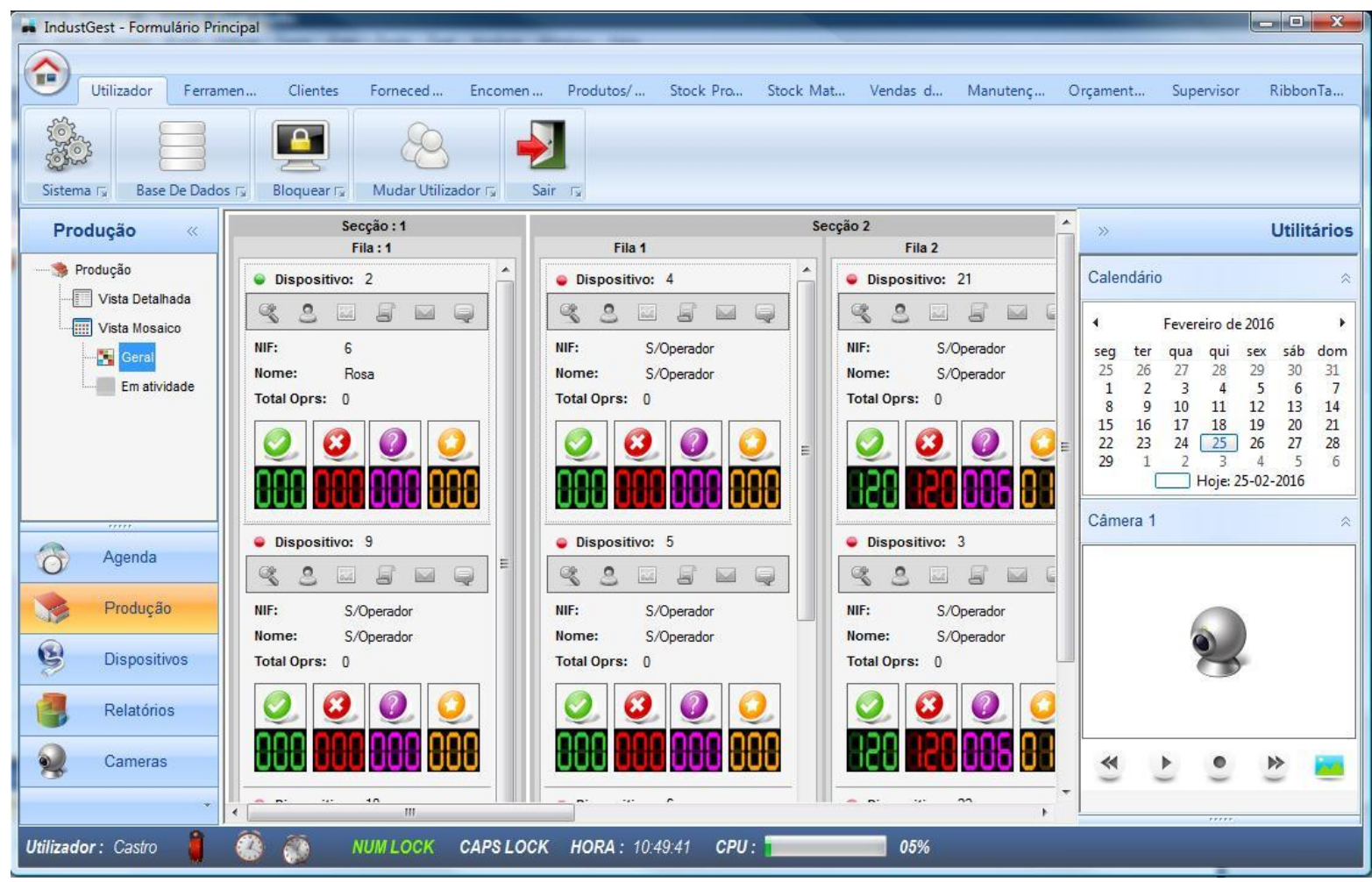

Figure 5: Operators assignment and control tool.

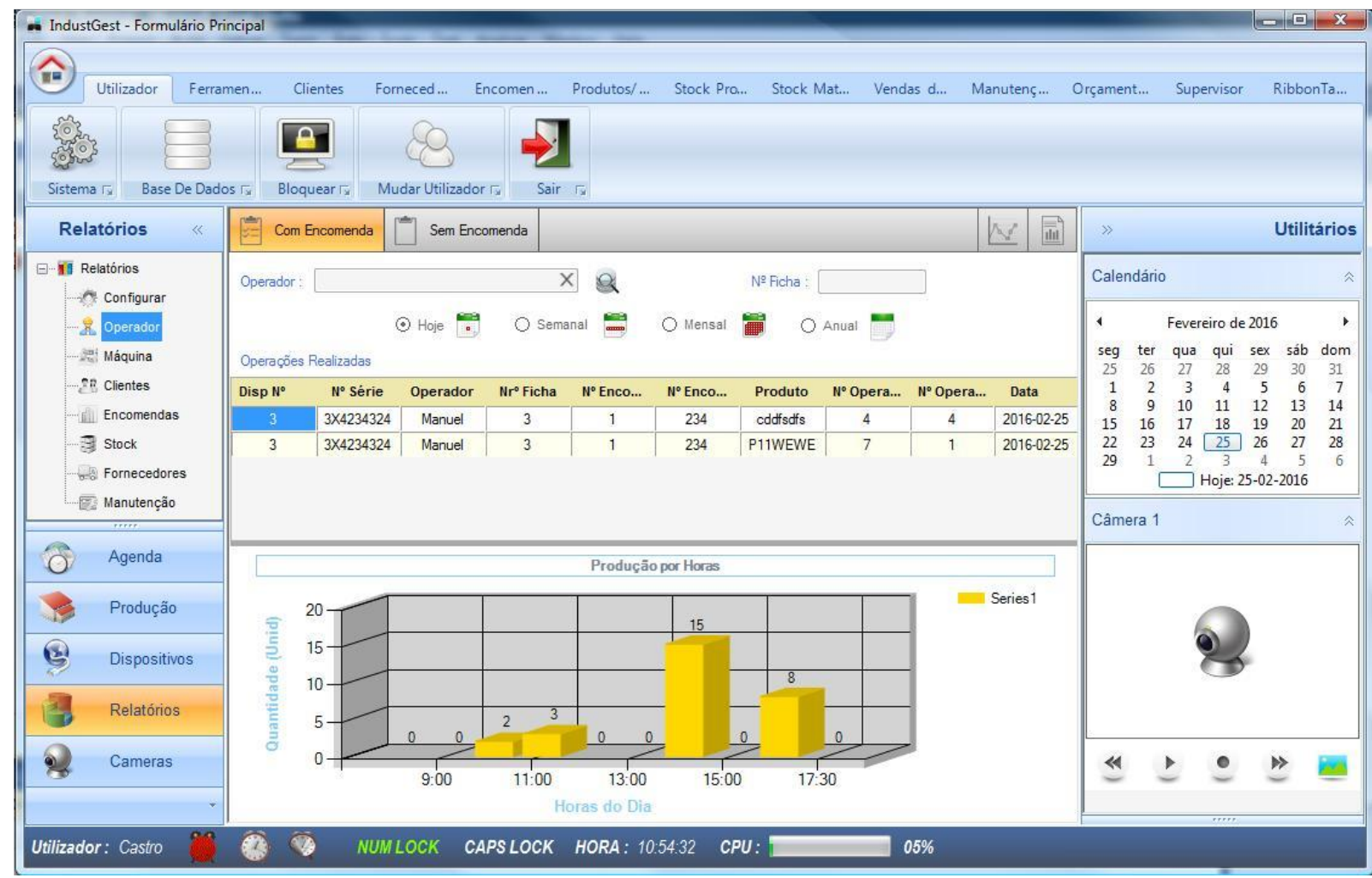

Figure 6: Integrated view of decision support tools. 


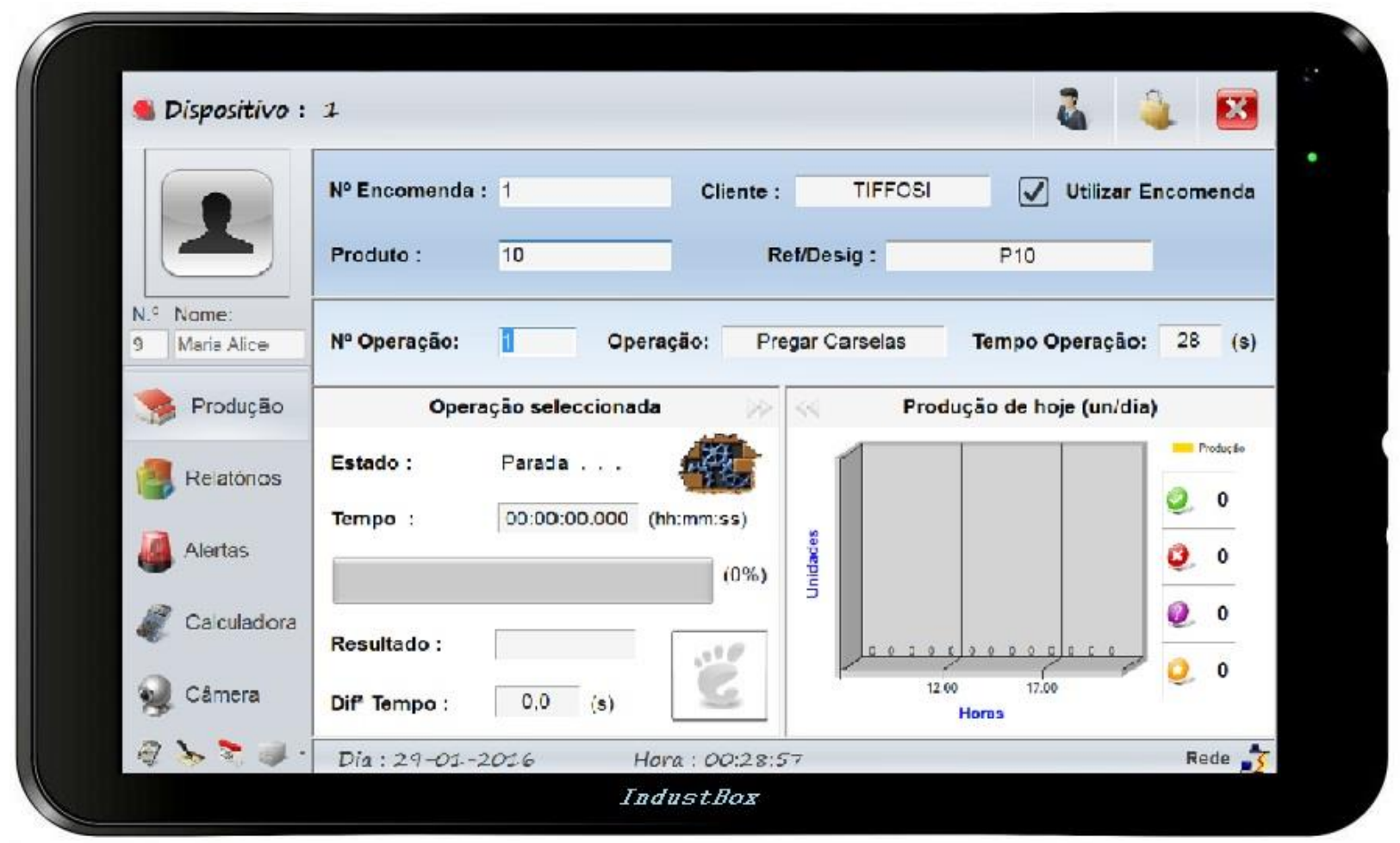

Figure 7: IndustBox software prototype.

\section{Conclusions}

This paper was described a proposed platform for supporting a wide range of industrial management functions through integrated modules and a knowledge based system (KBS) which enables data acquisition, processing and communication with different kind of machines, tools and industrial devices, including smart objects, for enabling to better support decision making in companies, and which was implemented in a textile factory. The proposed KBS integrates a set of technologies which enable to directly interact with machines and equipment in the shop floor for data acquisition and its subsequent processing for supporting industrial management decision making.

The effectiveness of the integrated technologies and approaches was briefly described and illustrated through the textile application example. An important aspect of the KBS is that data can be generated and visualized by computers and other devices, including the smart objects, in appropriate and distinct ways. Moreover, the data representation schema is general for distinct kind of manufacturing requisites.

For being able to fully implement the overall characteristics of the proposed KBS, there is still some need of further work to implement additional functionalities, for instance, the implementation of the proposed platform in other types of industrial scenarios will also be explored in the near future, in order to improve the platforms functionalities and perform additional tests and validation.

\section{Acknowledgment}

This work was supported by FCT "Fundação para a Ciência e a Tecnologia" under the program: PEst20152020.

\section{References}

[1] Alexandru, C. \& Gheorghe, G. (2014). The measurement characterisation of the mechatronic systems. Romanian Review Precision Mechanics, Optics and Mechatronics, Issue 45, 2014, Pages 6870

[2] Alexandru, C. \& Gheorghe, G. (2015). Mechatronic architectures. AIP Conference Proceedings Volume 1648, 10 March 2015, Article number 620003. International Conference on Numerical Analysis and Applied Mathematics 2014, ICNAAM 2014; Rodos Palace HotelRhodes; Greece; 22 September 2014 through 28 September 2014; Code 111492.

[3] Brewer, A., Sloan, N., \& Landers, T. L. (1999). Intelligent tracking in manufacturing. Journal of Intelligent Manufacturing, 10(3-4), 245-250.

[4] Courtois, A., Pillet, M., \& Martin-Bonnefous, C. (2007). Gestão da Produção: Para uma gestão industrial ágil, criativa e cooperante. Lisboa: LIDEL.

[5] Everett, R. R., Zraket, C., \& Benington, H. (1957). SAGE: A data-processing system for air defense. Paper presented at the Papers and discussions presented at the December 9-13, 1957, Eastern joint computer conference: Computers with deadlines to meet. 
[6] Gunasekaran, A., Ngai, E. W., \& McGaughey, R. E. (2006). Information technology and systems justification: A review for research and applications. European Journal of Operational Research, 173(3), 957-983.

[7] Haynes, M., McGregor, A., \& Stewart, N. (1997). The business team standard: A means of improving the effectiveness of individual businesses in a multibusiness corporation. Systems practice, 10(3), 219-239.

[8] López, T. S., Ranasinghe, D. C., Patkai, B., \& McFarlane, D. (2011). Taxonomy, technology and applications of smart objects. Information Systems Frontiers, 13(2), 281-300.

[9] Monostori, L., Csáji, B. C., Kádár, B., Pfeiffer, A., Ilie-Zudor, E., Kemény, Z., \& Szathmári, M. (2010). Towards adaptive and digital manufacturing. Annual Reviews in Control, 34(1), 118-128.

[10] Parmenter, D. (2010). Key performance indicators (KPI): developing, implementing, and using winning KPIs: John Wiley \& Sons.

[11] Soloman, S. (2009). Sensors and control systems in manufacturing (2 ed.): McGraw-Hill, Inc.

[12] Tanenbaum, A., \& Van Steen, M. (2007). Distributed systems: Pearson Prentice Hall. TECO. (2014). Technology for Pervasive Computing. Retrieved 2014, 4 de setembro, from http://particle.teco.edu/devices/index.html

[13] Vieira, G. G., Varela, L. R., \& Ribeiro, R. A. (2016). "A knowledge based system for supporting sustainable industrial management in a clothes manufacturing company based on a data fusion model", S. Liu et al (Eds.): Decision Support Systems VI - Addressing Sustainability and Societal Challenges (ICDSST 2016), Lecture Notes in
Business Information Processing (LNBIP) 250, pp. 113-126, 2016. DOI: 10.1007/978-3-319-32877-5_9.

[14] Voicu, A \& Gheorghe, G. (2014). Mechatronic adaptable equipment for highly precise integrated control of complex components from automotive industry, Romanian Review Precision Mechanics, Optics and Mechatronics, Issue 46, 2014, Pages 4045

[15] Wu, F., \& Kaiser, G. E. (1993). On Hard RealTime Management Information. Paper presented at the Systems Management, 1993., Proceedings of the IEEE First International Workshop on.

[16] Wu, J. (1998). Distributed System Design. Boca Raton: Taylor \& Francis.

[17] Zhang, Y., Huang, G. Q., Qu, T., Ho, O., \& Sun, S. (2011). Agent-based smart objects management system for real-time ubiquitous manufacturing. Robotics and Computer- Integrated Manufacturing, 27(3), 538-549.

[18] Zhang, Y., Jiang, P., Huang, G., Qu, T., Zhou, G., \& Hong, J. (2012). RFID-enabled real-time manufacturing information tracking infrastructure for extended enterprises. Journal of Intelligent Manufacturing, 23(6), 2357-2366.

[19] Zhekun, L., Gadh, R., \& Prabhu, B. (2004). Applications of RFID technology and smart parts in manufacturing. Paper presented at the ASME 2004 International Design Engineering Technical Conferences and Computers and Information in Engineering Conference.

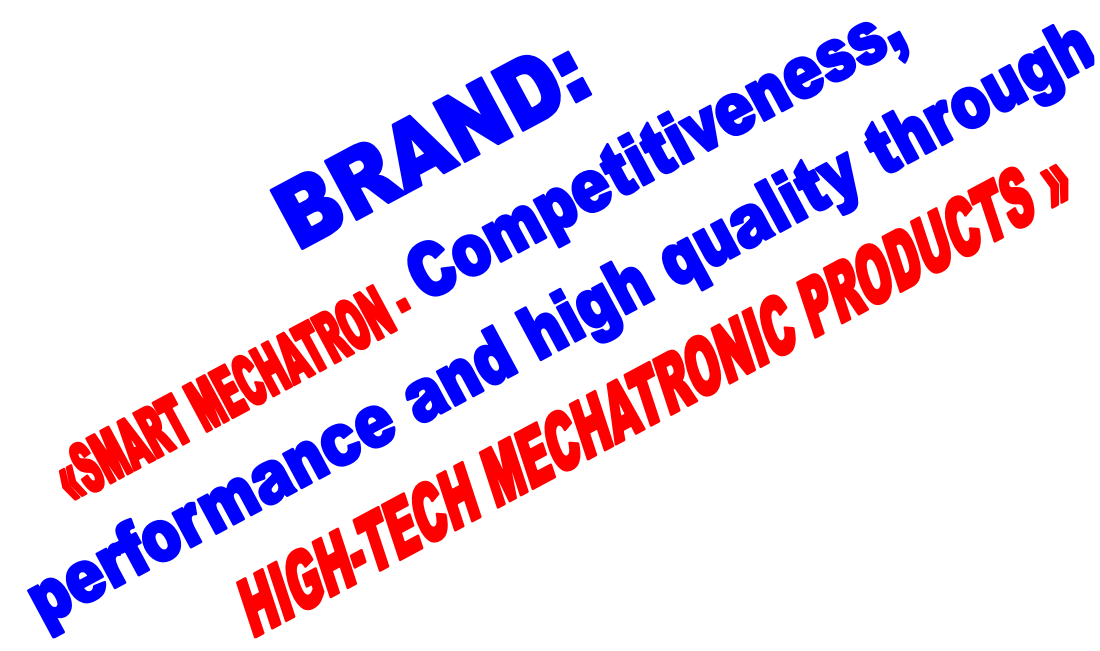


Copyright of Romanian Review Precision Mechanics, Optics \& Mecatronics is the property of Romanian Review Precision Mechanics, Optics \& Mecatronics and its content may not be copied or emailed to multiple sites or posted to a listserv without the copyright holder's express written permission. However, users may print, download, or email articles for individual use. 